\title{
Infância violada: crimes sexuais contra crianças (Ponta Grossa 1920-1930)
}

\begin{abstract}
Angela Ribeiro Ferreira ${ }^{1}$
Crianças...

São como pétalas de uma flor, tendo os espinhos como guardiões de sua pureza...

Exalam um perfume doce e por vezes erotizante.

São omissas, submissas, outras vezes vítimas de um ódio que é amor. Suas pétalas maculadas choram como bolhas de sabão atiradas ao chão.

Mãos valentes que as protegem sob o manto da autoridade

são as mesmas covardes que atacam sem piedade, porém sem rancor e, muitas vezes, ironicamente com amor...

Mãos irracionais, animais, por vezes carentes e inocentes, buscam insanamente destruir a vida que ajudaram a construir. O artesão pelo amor, transforma-se à luz da sociedade no "vilão" estuprador... A força da lei, soprando como desvairado vento pode abater de pronto todos os espinhos desprotegendo a pureza de seu pensamento.

E, pondo fim, enfim, como aos pássaros, os seus ninhos. ${ }^{2}$
\end{abstract}

\section{Introdução}

O presente ensaio é o resultado parcial de uma pesquisa que está sendo desenvolvida a um ano e meio, como trabalho de conclusão da disciplina Métodos e Técnicas de Pesquisa II, do curso de História. A proposta é analisar, através de crimes sexuais cometidos contra crianças, os sentimentos que permeavam e fundamentavam a infância na família e na sociedade pontagrossense do início do século. A problemática será respondida através da análise dos discursos jurídicos, que tratam de crimes sexuais envolvendo crianças. Tais discursos possibilitam o destaque de particularidades comportamentais que revelam valores culturais acerca da criança e da família. Os processos da 1a Vara Criminal da Comarca de Ponta Grossa constituem a documentação (fonte) utilizada na pesquisa. Especificamente nas décadas de 1920-30, existem vários casos de violência sexual relatados nos processos judiciais, destacando-se 12 casos de estupro ou atentados contra crianças ${ }^{3}$.

1 Graduação - História/UEPG.

2 SANTOS, Hélio de Oliveira. Crianças Violadas. CO-EDIÇÃO CBIA/CRAMI: Brasília. 1991.

3 Foram considerados apenas os crimes contra crianças com até 13 anos de idade, porque acima dessa idade, os casos caracterizam-se mais como defloramento. Aparecem como estupro porque todo crime - segundo o Có- 
No Brasil, de alguma forma, sempre houve preocupação por parte das autoridades em punir esses crimes. A princípio, a base das punições estava no Livro V do Código Filipino. No Código Criminal do Império, o estupro aparece no capítulo intitulado Crimes contra a segurança da honra. Em seguida, o Código Penal Republicano - nesta legislação os crimes sexuais recebiam o título de Crimes contra a segurança da honra e honestidade das família - e por último o Código Penal de 1940, vigente até hoje, que atribui aos crimes sexuais o título de Crimes contra os costumes.

A preocupação com a infância, embora lenta, vem se desenhando desde o final do século XIX. Já em 1899, surge no Rio de Janeiro o Instituto de Proteção e Assistência à Infância, com caráter filantrópico, que viria a ter uma filial no Paraná apenas em 1921, com sede em Curitiba. Em 1927, é criado o primeiro Código de Menores em que consta a preocupação com o trabalho infantil e com menores infratores. Em 1979 ocorre a revisão desse código, e finalmente, em 1990, é elaborado o Estatuto da Criança e do Adolescente.

\section{Processos Criminais: uma fonte muito fértil}

A utilização de registros judiciais como fonte necessita de alguns cuidados por parte do historiador. Ao se tratar de crimes e famílias desestruturadas, como é o caso da violação de crianças, está se tratando de exceções e não de regras de comportamento. As circunstâncias em que o crime acontece não são um retrato do cotidiano e sim, como coloca Peter Burke $^{4}$, acontecimentos extraordinários, não comuns na vida das pessoas. O processo é uma construção do real, traduzindo não só o crime, mas todo o jogo jurídico que se instaura para punir ou absolver.

"No momento em que os atos se transformam em autos, os fatos em versões, o concreto perde quase toda a sua importância e o debate se dá entre os atores jurídicos, cada um deles usando a parte do 'real' que melhor reforce o seu ponto de vista". ${ }^{5}$

Assim, tomando os cuidados necessários, lendo nas entrelinhas e levando em consideração que todos os discursos são socialmente produzidos, os registros judiciais podem ser uma fonte muito rica para o estudo da sexualidade.

Além das falas da Defesa, Acusação e depoimentos, que neste

digo Penal de 1890 - cometido contra menor de 16 anos presume-se praticado com violência.

4 BURKE, Peter. A Escrita da História: Novas Perspectivas. Unesp: SP, 1992. (p.25).

5 Mariza Corrêa. Morte em Família.1983, p.40. Citado em FAUSTO, Boris. Crime e Cotidiano: A criminalidade em São Paulo (1880-19240). Brasiliense: SP, 1984. (p.21-22). 
trabalho constituem peças fundamentais, vários dados podem ser extraídos dos processos; elementos variáveis que vêm complementar a análise dos discursos: idade, profissão, instrução, naturalidade e estado civil do réu, natureza do crime, relação réu/vítima, idade das vítimas, situação social dos envolvidos. Neste trabalho específico esses elementos são reveladores.

Dentre os 12 casos considerados na pesquisa, cerca de $83 \%$ dos crimes foram praticados por pessoas da família, ou por alguém muito próximo do convívio da criança, ou de sua confiança. Um número muito parecido se encontra em pesquisas realizadas recentemente em São Paulo ${ }^{6}$. Essas pesquisas apontam a família como principal violentadora sexual de crianças e adolescentes, principalmente de atos cometidos contra meninas.

No que diz respeito à condição social dos envolvidos, a grande maioria dos acusados, cerca de $80 \%$, pertencem à classe menos favorecida - o que se mostra através de profissões pouco remuneradas ${ }^{7}$ - e pelos locais de residência, bairros que até então faziam parte da periferia da cidade de Ponta Grossa. É muito provável que os crimes entre as classes economicamente abastadas fossem resolvidos no próprio espaço privado.

O perfil das famílias das vítimas é bem variado. Em 5 casos a vítima pertence a famílias desestruturadas ${ }^{8}$, ora só tem o pai, ora só a mãe, ou mora na casa de parentes (avós, tios, irmãos). Além disso, o crime sexual contra a infância revela-se uma violência predominantemente urbana. Dos 12 casos que foram catalogados, 9 aconteceram na cidade de Ponta Grossa e 3 na área rural.

Quanto à idade das vítimas, mais da metade tem até 9 anos. Poder-se-ia partir do pressuposto de que a "escolha" da vítima pelo seu algoz fosse feita mais pela fragilidade, pela dificuldade de resistência e defesa, do que pela nubilidade de seus $\operatorname{corpos}^{9}$. Embora hoje se saiba que muitos desses agressores têm atração sexual justamente pela criança, é possível que realmente as escolhessem pela pouca força e não pelas formas do seu corpo.

Outro dado que chama a atenção é o fato de aparecerem apenas denúncias de violência sexual contra meninas. Isso não quer dizer que não acontecessem agressões contra meninos, mas demonstra que tais casos

6 PASSETTI, Edson. Violentados: Crianças, Adolescentes e Justiça. SP: Imaginário, 1999.

7 Dos 12 acusados, eram: 3 lavradores, 2 ferroviários, 2 operários, 1 professor particular, 1 empregado do comércio, 1 industrial, 1 pintor e mecânico, 1 professor particular e lavrador.

8 Desestruturadas, de acordo com o modelo tradicional de família do início do século. Definição dada segundo dados empíricos.

9 VIGARELLO, Georges. História do Estupro: Violência Sexual nos Séculos XVI-XX. Trad. Lucy Magalhães. RJ: Jorge Zahar Editor, 1998. (p. 166). Nubilidade significa estar em idade de casar. E Vigarello se utiliza dessa expressão dizendo que o agressor escolhe sua vítima mais pela fragilidade física, do que pela atração do corpo ainda infantil.

8

Qevista Xernáculo 
eram resolvidos em outras instâncias sociais, ou simplesmente silenciados. A violência contra meninas envolve uma série de valores acerca da virgindade feminina, deixando evidente que a maior preocupação não é com a prática da violência em si, mas com a honra perdida, caracterizada pela virgindade, considerada atestado de honestidade e componente de honra, o que de certa forma justifica as denúncias.

\section{Inocência roubada: Infância e Violência}

Um caso, entre todos os catalogados, se destaca pela riqueza discursiva. É o caso das irmãs M. J. e F. ${ }^{10}$, violentadas por Santiago Almeida Cardoso, um operário de 36 anos, solteiro, brasileiro (natural de São Paulo), residente no Bairro Nova Rússia em Ponta Grossa. A promotoria pública apresenta a seguinte denúncia:

"No dia 24 de setembro p. findo, pelas 21 horas, no bairro Nova Rússia, nesta cidade, o denunciado penetrou às ocultas na casa de seu vizinho P. C. da C, e aí, armado de navalha, sob ameaças, se apoderou violentamente de duas filhas menores deste, M. J. dos S. C. e F. S. C, de 12 e 11 anos de idade, respectivamente, fechando-se com elas num dos quartos da casa.

No quarto, o denunciado deitou violentamente a menor $M$. J. sobre uma cama, e a estuprou, não obstante a resistência e os gritos de dor da infeliz criança. Após a prática dessa monstruosidade, o denunciado ainda apoderou-se a viva força da menor $F$. e tentou do mesmo modo estuprá-la, procurando introduzir-Ihe, sem o conseguir, o membro viril na vagina." 11

Assim que ficou sabendo, alguns dias depois, o pai das vítimas levou o caso ao conhecimento da polícia. A mãe das meninas não havia contado imediatamente ao marido, com receio das ameaças do agressor. O crime aconteceu no dia 24 de setembro de 1936 e a queixa foi apresentada à polícia somente no dia 2 de outubro do mesmo ano. Rapidamente, o Delegado Cel. Adolfo Guimarães, determina que seja instaurado inquérito a respeito, afim de apurar a responsabilidade do criminoso ${ }^{12}$, solicitando em seguida os exames de corpo de delito nas vítimas.

"Ouvidas as testemunhas estas são unanimes em afirmar que o indiciado é um indivíduo perigoso de péssimos antecedentes tornando-se

10 Por motivos considerados, particularmente, importantes, que é o respeito à pessoa das vítimas, os nomes foram omitidos.

11 Processo Santiago Almeida Cardoso, Ano 1936, Caixa 2, p. 1.

12 Processo Santiago Almeida Cardoso, Ano 1936, Caixa 2, p.2. 
assim um elemento pernicioso à sociedade. O indiciado nas suas declarações confessou cinicamente que de fato praticou o hediondo crime, declarações estas feitas de sua livre e espontânea vontade."13

No exame de corpo de delito, feito pelos médicos Dr. Antonio Penteado de Almeida e Dr. Joaquim Loyola, se confirma a violência. Na menor F., de 11 anos, os peritos encontraram a membrana hímen intacta, porém com sinais de tentativa violenta de introdução do pênis. Já em M. J., 12 anos, os peritos examinaram e observaram

"os grandes lábios edemaciados e avermelhados dolorosos, afastados deixaram ver a membrana hímen completamente dilacerada, e ferimentos em ambos os lados e face interna dos grandes lábios. Nota-se também corrimento." 14

No relatório final do inquérito policial, o delegado pede ao juiz a prisão preventiva do acusado. A promotoria concorda e confirma o pedido de prisão preventiva, alegando tratar-se o acontecido

"de um delito que fere intimamente o que a sociedade tem de mais valioso: a honra pessoal de seus componentes a instituição familiar. Com a prática do delito de que é acusado, Santiago Almeida Cardoso, além de destruir o que a sua vítima tinha de mais sagrado, com esse seu ato, impediu, quase certo a formação de uma futura família, tendo sua vítima como base.

A natureza do delito, as circunstancias como ele foi praticado, tudo indica gritando que a temibilidade do indiciado é perigosíssima ao meio social. O acusado, pelos seus instintos perversos e desumanos, requer e necessita sua exclusão do ambiente social. Sua liberdade é uma ameaça continua: é uma promessa de futuros delitos. ${ }^{15}$

O promotor público diz ainda que a prisão do acusado se impõe como verdadeira medida de segurança e profilaxia social ${ }^{16}$. Baseado nesses argumentos o juiz decreta a prisão preventiva, embora o defensor Dr. Newton Souza e Silva tenha tentado enquadrar o crime como fruto de uma aberração sexual e não uma vontade criminosa consciente ${ }^{17}$, pedindo que o réu fosse internado para sua reabilitação.

Comprovada a materialidade do crime, o réu foi condenado no dia primeiro de dezembro de 1936, pelo juiz Edison Nobre de Lacerda, a

\footnotetext{
13 Processo Santiago Almeida Cardoso, Ano 1936, Caixa 2, p. 12 v.

14 Idem.

15 Processo Santiago Almeida Cardoso, Ano 1936, Caixa 2, p. 16.

16 Idem.

17 Processo Santiago Almeida Cardoso, Ano 1936, Caixa 2, p.40).
} 
dez anos de prisão celular - a ser cumprida na Penitenciária do Ahú - grau máximo das penas do art. 268 combinado com os artigos 269, 272 e 276 ${ }^{18}$, todos do Código Penal de 1890. Além disso, o condenado teria de pagar as custas, a taxa da Penitenciária, e dotar ${ }^{19}$ a menor ofendida.

O réu cumpriu parte da pena e em 16 de fevereiro de 1943, pede ao Conselho Penitenciário do Estado o seu livramento condicional. E em 29 de outubro de 1958, o processo foi arquivado.

\section{Infância, Violência, Sexualidade \& Historiografia}

As noções de infância e de família sofreram transformações ao longo do tempo, na medida em que novos valores foram sendo culturalmente construídos. As transformações ocorridas referem-se ao tratamento dispensado à criança.

Na Idade Média, a função afetiva da família em relação a criança não era tão valorizada, o amor, tal como o conhecemos hoje, não era necessário para o equilíbrio da família, como ressalta ARIÈS ${ }^{20}$.

"O sentimento de infância não existia - o que não quer dizer que as crianças fossem negligenciadas, abandonadas ou desprezadas. O sentimento da infância não significava o mesmo que afeição pelas crianças: corresponde à consciência da particularidade infantil, essa particularidade que distingue essencialmente a criança do adulto, mesmo jovem. Essa consciência não existia."

A família moderna manifesta preocupações mais íntimas com a criança, que passa a ser mais preservada. Agora a família se organiza em torno da criança, constituindo um modelo mais intimista, determinando o espaço de convivência entre adultos e crianças. Com o início da educação escolar - em substituição à aprendizagem medieval - novas práticas e valores morais passaram a ser empregados na educação e as crianças passaram a ficar mais tempo com a família, criando vínculos afetivos. Segundo Ariès, é a partir da Idade Moderna, com uma maior aproximação entre pais e filhos, que começa a nascer a afetividade, o sentimento de infância e de

\footnotetext{
18 "Art. $268^{\circ}$ Estuprar mulher virgem ou não, mas honesta.
}

Art. 269" Chama-se estupro o ato pelo qual o homem abusa com violência de uma mulher, seja virgem ou não. Por violência entende-se não só o emprego da força física, como o de meios que privarem a mulher de suas faculdades físicas, e assim da possibilidade de resistir e defender-se, como sejam o hipnotismo, o clorofórmio, o éter, e em geral os anestésicos.

272" Presume-se cometido com violência qualquer dos crimes especificados neste e no capítulo precedente, sempre que a pessoa ofendida for menor de 16 anos.

Art $276^{\circ}$ Nos casos de defloramento, como nos de estupro de mulher honesta, a sentença que condenar o criminoso o obrigará a dotar a ofendida".

19 Pagar um dote, espécie de indenização.

20 ARIĖS. Philippe. História Social da Criança e da Família. Trad. Dora Flaksman. Afiliada, 1981. p. 156). 
família. É a partir daí que acontece um isolamento da família em relação à coletividade, a valorização da privacidade.

O século $X X$ é caracterizado por uma crescente preocupação e profissionalização dos cuidados com a criança, porém diante de tantas mudanças no trato com a infância, ocorre uma volta ao passado - as crianças novamente ficam pouco tempo com a família, embora os motivos sejam outros e existam os laços afetivos. O fato é que neste século, tempo em que os pais trabalham fora, a criança acaba sendo educada não só pela família, mas por profissionais da educação ( professores ) durante boa parte do dia.

Entretanto, a incidência de casos de violência sexual contra a criança, nas décadas de 1920 e 1930, em Ponta Grossa, revela que a teia de proteção que se estabeleceu no século XX não impediu a ocorrência dos crimes. O caso das duas irmãs exemplifica isto, a preocupação mais visível nas falas, no decorrer no processo, é com a suposta perda da honra e não com a prática da violência. Na voz do promotor é possível identificar claramente essa preocupação com a honra, quando ele argumenta que o acusado destruiu o que a vítima tinha de mais sagrado, motivo pelo qual a menina jamais poderia ser a base de uma futura família.

Apenas recentemente as pesquisas tendo a criança como objeto se tornaram expressivas com o advento da Nova História Cultural. A abordagem cultural dedica especial atenção aos esquecidos, ao cotidiano, à família, à criança, ao contrário da historiografia tradicional que limitava-se a grandes acontecimentos c fatos.

A bibliografia sobre a criança não é muito vasta, mas alguns trabalhos ganharam um espaço significativo nas últimas décadas:

- $\quad$ Philippe Ariès, com a obra História Social da Criança e da Família, que data originalmente de 1960, se tornou referência para todas as pesquisas sobre a criança. Em sua obra, ele trata da criança e da vida familiar, na França do Antigo Regime; trata do surgimento do sentimento de infância e de família, do isolamento da família em relação à coletividade e da valorização da privacidade.

- $\quad$ Boris Fausto, embora em sua obra Crime e Cotidiano: A criminalidade em São Paulo (1880-1924), não aborde especificamente de crianças como objeto, ele trata de criminalidade, controle social e crimes sexuais, destacando tudo o que envolve os discursos, as preocupações sobre o crime.

- $\quad$ Georges Vigarello, na obra História do Estupro: Violência Sexual nos Séculos XVI-XX, mostra toda a trajetória do surgimento 
da sensibilidade em relação aos crimes sexuais na França. No Antigo Regime, existia uma certa tolerância em relação ao estupro, o qual era visto, a princípio, como crime moral. No século XVIII começam a se esboçar algumas mudanças, aumenta o número de queixas, e nos processos se revela a presença da opinião pública. Em meados do século XIX, surgiram mudanças significativas, reconhecimento da violência, o código é revisto, o nascimento da psicopatologia e uma acentuada sensibilidade à violência. Já em fins do século XIX surgem teorias, como a de Lombroso, que tentam explicar os crimes sexuais através de características físicas do criminoso. Os crimes são nitidamente mais condenados, mas persiste a preocupação da possível depravação da vítima. Segundo ele, o estupro se tornou a violência do nosso tempo.

- Michel Foucault, no livro História da Sexualidade I: a vontade do saber, elabora o trabalho em torno da hipótese repressiva, não dizendo que ela seja falsa, mas mostrando que ela não é o elemento essencial para se pensar a sexualidade; a hipótese assume outra dimensão. Nesse sentido, faz uma análise do que ele chamou de explosão dos discursos sobre o sexo. Para Foucault, nunca se falou tanto em sexo, no entanto com decência nas expressões, censura no vocabulário.

Embora bastante criticado, pela ausência de uma preocupação com práticas sexuais reais, Foucault tem um mérito indiscutível; suas idéias abalaram e mexeram com pressupostos, concepções e certezas sobre as quais se assentavam muitas das perspectivas da análise histórica. ${ }^{21}$

\section{Considerações finais}

Como a pesquisa ainda não foi concluída, certamente muitas outras questões surgirão. No decorrer do texto tento mostrar como um crime sexual contra uma criança, um ato que trás tantos transtornos físicos e emocionais às vítimas, pode se transformar numa preocupação moral, preocupação com a honra perdida. Vigarello comenta que as primeiras décadas do século $X X$ não são as mais importantes ${ }^{22}$ no que se refere às transformações ocorridas nas punições dos crimes sexuais. Entretanto, no Brasil vários movimentos sociais ganham espaço. Em especial os movimentos feministas, que indireta e lentamente, começam a interferir no modo de ver a mulher, consequentemente, na questão da honra, da virgindade e nas formas de perceber a violência contra as minorias sociais.

21 ENGEL, Magali. História e Sexualidade. In: CARDOSO, Ciro Flamarion; VAINFAS, Ronaldo. Domínios da História: ensaios de teoria e metodologia. Campos: RJ, 1997.

22 VIGARELLO, Georges. História do Estupro: Violência Sexual nos Séculos XVI-XX. Trad. Lucy Magalhães. RJ: Jorge Zahar Editor, 1998. (p. 206). 


\section{Referências Bibliográficas}

ARIĖS, Philippe. História Social da Criança e da Família. Trad. Dora Flaksman. Afiliada, 1981.

BASTOS, José Tavares. Código Penal Brasileiro. C. Teixeira \& C: SP, 1918.

BURKE, Peter (org.). A escrita da História: novas perspectivas. Trad. Magda Lopes. Unesp: SP, 1992.

ENGEL, Magali. História e Sexualidade. In: CARDOSO, Ciro Flamarion: VAINFAS, Ronaldo. Domínios da História: ensaios de teoria e metodologia. Campos: RJ, 1997.

FAUSTO, Boris. Crime e Cotidiano: A criminalidade em São Paulo (18801924). Brasiliense: SP, 1984.

FOUCAULT, Michel. História da Sexualidade 1: a vontade do saber. Trad. Maria Thereza da C. Albuquerque e J. A. Guilhon Albuquerque. Graal: RJ, 1988.

MORELLI, Ailton José. A criança e o "menor": pequeno balanço bibliográfico. In: Revista Diálogos, UEM, 1997.

PASSETTI, Edson. Violentados: Crianças, Adolescentes e Justiça. Imaginário: SP, 1999.

SANDIM, Bengt. Imagens em conflito: Infâncias em mudança e o Bemestar social na Suécia. Reflexões sobre o século da criança. In: Revista Brasileira de História. V. 19, n 37, p. 15-34. SP, 1999.

SANTOS, Hélio de Oliveira. Crianças Violadas. CO-EDIÇÃO CBIA/CRAMI: Brasília, 1991.

VIGARELLO, Georges. História do Estupro: Violência Sexual nos Séculos XVI-XX. Trad. Lucy Magalhães. Jorge Zahar Editor: RJ, 1998. 